

\section{Growth of mono- and mixed cultures of Nannochloropsis salina and Phaeodactylum tricornutum on struvite as a nutrient source}

Ryan W. Davis ${ }^{a^{*}}$, Anthony J. Siccardi III' ${ }^{\mathrm{b}}$ Nathan D. Huysman ${ }^{\mathrm{b}}$, Nicholas B. Wyattc, John C. Hewsonc and Todd W. Lane ${ }^{\mathrm{a}}$

aSandia National Laboratories, Livermore CA

bTexas AgriLife Research Mariculture Laboratory, Corpus Christi TX

cSandia National Laboratories, Albuquerque NM

\section{Abstract}

The suitability of crude and purified struvite $\left(\mathrm{MgNH}_{4} \mathrm{PO}_{4}\right)$, a major precipitate in wastewater streams, was investigated for renewable replacement of conventional nitrogen and phosphate resources for cultivation of microalgae. Bovine effluent wastewater stone, the source of crude struvite, was characterized for soluble N/P, trace metals, and biochemical components and compared to the purified mineral. Cultivation trials using struvite as a major nutrient source were conducted using two microalgae production strains, Nannochloropsis salina and Phaeodactylum tricornutum, in both lab and outdoor pilot-scale raceways in a variety of seasonal conditions. Both crude and purified struvite-based media were found to result in biomass productivities at least as high as established media formulations (maximum

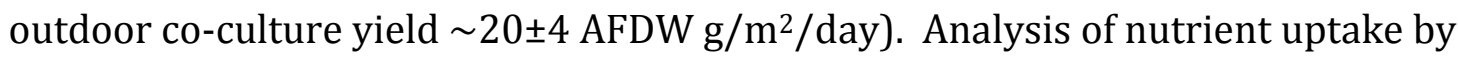
the alga suggest that struvite provides increased nutrient utilization efficiency, and

*Corresponding author email: rwdavis@sandia.gov 
that crude struvite satisfies the trace metals requirement and results in increased pigment productivity for both microalgae strains.

\section{Introduction}

Cultivation of microalgae presents the possibility for sustainable production of bioproducts, feeds, and fuels. To achieve this goal, a number of technical challenges must be met for reducing the costs of algae biomass production and processing, including balancing space needs, productivity and biomass concentrations, and energy and nutrient requirements. In a recent lifecycle analysis of full scale algae production for fuels, the major nutrients - nitrogen and phosphorus - were identified as the single largest cost contributor ( $>30 \%$ of the total) (Liu et al., 2013). On a national scale, displacement of $\sim 10 \%$ of the U.S. transportation fuels demand by algae was calculated to require a significant fraction of current domestic fertilizer use (Pate et al., 2011), presenting the likelihood of food versus fuels crises and therefore limiting the ultimate sustainability of algae-based fuels if nutrient recycling is not included in the process. While nutrients are the single largest cost contributor, other costs which need to be addressed involve biomass harvesting and dewatering and extraction and conversion of individual value-added algal components (Greenwell et al., 2010).

Low-energy intensity major nutrient (N/P) regeneration and methods for fertilizer precision application have been identified as critical scientific and technological breakthroughs required for sustainable global development (Buluswar et al., 2014). Although ammonia can be synthesized from atmospheric nitrogen in the Haber-Bosch process, the manufacture is dependent on the 
availability of natural gas resources. Phosphate is a non-renewable (mined) resource. The results of multiple resource assessment studies indicate that current phosphorus reserves will be depleted in the $21^{\text {st }}$ century (Lougheed, 2011); demand for biomass-based energy is expected to accelerate this phenomenon (Neset \& Cordell, 2012). In addition to cost and sustainability concerns, uncontrolled phosphate release is a major contributor to eutrophication (Smil, 2000) and associated ecological collapse in waterways (e.g. the Gulf of Mexico "Dead Zone"). Extraction of phosphorus-rich materials from waste processing provides a means for phosphate management and recycling (Tchobangolous et al., 2003) that could minimize downstream impacts and depletion of strategic reserves. In concentrated waste streams, such as animal feeding operations and wastewater treatment facilities, phosphate precipitates spontaneously to form struvite $\left(\mathrm{NH}_{4} \mathrm{MgPO}_{4}\right)$ and calcium phosphate salts, resulting in pipe fouling and increased maintenance costs (Fattah, 2012). Multiple technical approaches have been explored for high efficiency (up to 90\%) recovery of struvite from wastewaters, including collection of crystallized precipitates (Marti et al., 2010), and by employing optimized fluidized bed reactors (Bhuiyan et al., 2008) and regenerative ion exchange materials (Sengupta, 2013). A case study investigating the potential for using digester recovered struvite concluded that the levels of heavy metal and micropollutants were within acceptable tolerances for use as an agricultural fertilizer (Uysal et al., 2010). Other options for nutrient recovery from wastestreams using microalgae include direct and indirect usage of nutrients from 
industrial and agricultural wastewaters and anaerobic digester effluent (Cai et al., 2013).

The goal of this study was to determine whether struvite could serve as a suitable replacement for the nitrogen and phosphorous requirements for algae cultivation. Therefore, the effect of replacement of conventional nutrients with purified and crude struvite on the productivity was two microalgae production strains (Nannochloropsis salina and Phaeodactylum tricornutum) was investigated in both lab and outdoor trials, with comparison to established growth medium formulations. The struvite sources were characterized for total soluble nitrogen and phosphorus, trace metals, and potential organic carry-overs, including sugars and proteins. Various nutrient replacement regimes were investigated to evaluate the potential for slow release effects and other modified nutrient uptake phenomena and how these impact biomass productivity (Klausmeier et al., 2004). All of the algal growth studies were conducted in batch, and in addition to biomass productivity, phenotypic variables including cell size, number, and chlorophyll content were assessed. Pilot-scale algae raceway studies of mono- and mixed cultures of Nannocholropsis and Phaeodactylum were conducted to identify seasonal effects. These data include supporting information incorporating solar flux, temperature, wind speed, precipitation, and culture $\mathrm{pH}$ and salinity. Paired with advances for efficient harvesting a product recovery, the results presented here should be applicable for advancing sustainable and economically viable algae cultivation for renewable products and biofuels. 


\section{Materials and Methods}

\subsection{Microalga strains}

Nannochloropsis salina (CCMP 1776) and Phaeodactylum tricornutum (CCMP 632) were obtained from the National Center for Marine Algae and Microbiota (NCMA) at Bigelow Laboratory for lab-scale cultivation assays. N. salina (CCMP 1776) and a local isolate of Phaeodactylum tricornutum (isolated from the Laguna Madre, Corpus Christi, TX) were employed for outdoor cultivation at Texas Agrilife, Corpus Christi, TX, in 557L raceway systems. Strain selection was based on the intent to evaluate phenotypically distinct production strains to identify major variations in struvite utilization; demonstrated robust productivity of each species in outdoor culture; complementary production seasons between the two species (N. salina has high biomass productivity in the late spring through early fall season, $P$. tricornumtum has high biomass late fall through early spring in South Texas); and demonstrated compatibility of the two species for high net productivity co-culture.

\subsection{Media compositions and struvite sources}

For lab-scale assays, the control culture medium was L1 enriched artificial seawater adjusted to $\mathrm{pH} 8.0$; the specific formulation is provided in S1. For these trials, experimental media compositions using struvite as a partial or complete $\mathrm{N}$ or $\mathrm{P}$ source were generated using artificial seawater, varying levels of struvite with supplementation of sodium nitrate and dibasic sodium phosphate as necessary, and the trace metals and vitamins, except where denoted otherwise. For pilot-scale outdoor growth trials, the control culture medium was composed of local filtered seawater, $2.0 \mathrm{mM}$ nitrogen (from ammonium sulfate), $0.13 \mathrm{mM}$ phosphorus (from 
phosphoric acid) (16:1 N:P ratio) and $0.07 \mathrm{mM}$ iron (from iron sulfate), see S1. This medium has been demonstrated to yield growth rates equivalent to more costly medium formulations in outdoor cultivation. For nutrient replacement trials, experimental media compositions using struvite as a partial or complete $\mathrm{N}$ or $\mathrm{P}$ source were generated using local seawater and varying levels of struvite with supplementation of ammonium sulfate and phosphoric acid as necessary. Struvite was acquired as the purified hydrate $\left(\mathrm{NH}_{4} \mathrm{MgPO}_{4} \bullet 6 \mathrm{H}_{2} \mathrm{O}\right.$, Sigma-Aldrich and Multiform Harvest, Inc., Seattle, Washington), and in crude form (as wastewater stone) from a Boise, Idaho based wastewater treatment facility managing effluent from a concentrated animal feeding operation for cattle (the generous gift of Gary Westlund, Guard Products, Inc.).

\subsection{Culture conditions}

\subsubsection{Lab-scale growth assays}

Cultures of N. salina (CCMP 1776) and P. tricornutum (CCMP 632) were inoculated with late-log phase axenic cultures to achieve starting near-IR optical densities of $\sim 0.05-0.10$ in a MC1000 multicultivator apparatus (Photon Systems Instruments). The system was configured for constant air bubbling in each culture tube (200 $\mathrm{cm}^{3} / \mathrm{min}$ ) and a light/dark diurnal cycle of $16 / 8$ hours, with a sinusoidal light cycle corresponding to a photosynthetically active radiation (PAR) irradiance maximum of $1,000 \mu \mathrm{mol}$ photons $/ \mathrm{m}^{2} / \mathrm{sec}$ and minimum of $<25 \mu \mathrm{mol}$ photons $/ \mathrm{m}^{2} / \mathrm{sec}$, measured using a US-SQS/L spherical micro-quantum sensor positioned inside the medium-filled culture tubes. The temperature of the chamber was calibrated to $21^{\circ} \mathrm{C}$ during the dark cycles and gradually increased to $26^{\circ} \mathrm{C}\left( \pm 0.5^{\circ} \mathrm{C}\right)$ following the 
peak of the sinusoidal light cycle. Additional data regarding the lab-scale culture parameters are provided in Table 1. For phosphorus replacement assays, experimental treatments ( $\mathrm{n}=3$ each) were supplemented with purified or crude struvite to replace 33,67 and $100 \%$ of the phosphorus in the control treatment with and without the addition of trace metals and vitamins.

\subsubsection{Pilot-scale outdoor growth assays}

Cultures of N. salina (CCMP 1776), P. tricornutum (local isolate), or a mixture of the cultures (1:1 based on ash-free dry weight, AFDW, for phosphate replacement; 4:1 based on cell count for nitrogen replacement) were stocked into 12 outdoor raceways (557 L at $20 \mathrm{~cm}$ depth) at an initial stocking density of $\sim 0.15 \mathrm{~g} / \mathrm{L}$ AFDW at $5 \mathrm{~cm}$. Seawater used in the trials was pumped from the Laguna Madre, Corpus Christi, TX. Incoming seawater was filtered through a diatomaceous filter (Pentair Pool Products, Sanford, NC), chlorinated to $15 \mathrm{ppm}$ (minimum duration of 30 minutes) and then stored until use. Each raceway was fitted with a paddlewheel to provide a water flowrate of $50-60 \mathrm{~cm} /$ second and a $\mathrm{CO}_{2}$ injection system; $\mathrm{CO}_{2}$ injection was controlled to maintain the $\mathrm{pH}$ at 7.8. The control raceways $(\mathrm{n}=3)$ were supplemented with our standard nutrient blend (Zmora \& Richmond, 2007) to achieve $2.0 \mathrm{mM}$ nitrogen (from ammonium sulfate), $0.13 \mathrm{mM}$ phosphorus (from phosphoric acid) and $0.07 \mathrm{mM}$ iron (from iron sulfate) at 16:1 N:P ratio for the phosphorus replacement trials and 1:1 N:P ratio for nitrogen and phosphorus replacement trials. For the nutrient replacement trials, experimental treatments ( $n=3$ each) were supplemented with struvite (Multiform Harvest; Seattle, WA) to replace 33,67 and $100 \%$ of the nutrients in the control treatment; either $\mathrm{N}$ or $\mathrm{P}$ is 
replaced at this level as indicated below. The experimental raceways were then supplemented with ammonium sulfate, phosphoric acid (if necessary) and iron sulfate to balance nutrient levels with those in the controls. Water depth in each raceway was gradually increased to a final depth of $20 \mathrm{~cm}$. Raceways were monitored daily for solar radiation, rainfall, wind-speed, $\mathrm{pH}$, temperature, salinity, AFDW, ammonia and phosphate. Trials were terminated after 15 days of culture.

\subsection{Analytical methods}

\subsubsection{Struvite characterization}

The struvite samples were analyzed for elemental composition, soluble ammonium and phosphate, trace metals, the presence of proteins and carbohydrates, and for crystallographic confirmation of the struvite mineral lattice. Independent elemental analyses were performed by Micro Analysis, Inc. and New Jersey Feed Laboratory, Inc. Quantitative analysis of soluble ammonium was performed on saturated solutions of struvite in artificial seawater using the modified Berthelot colorimetric assay (Abcam, Inc) in 96-well format using an ammonium chloride standard dissolved in artificial seawater, with absorbance measured at $670 \mathrm{~nm}$. Quantitative analysis of soluble phosphate was performed on saturated solutions of struvite in artificial seawater using a malachite green colorimetric assay (Abcam, Inc) in 96well format using a dibasic sodium phosphate standard in artificial seawater, with absorbance measured at $670 \mathrm{~nm}$. Absence of proteins was confirmed colorimetrically from saturated solutions of the crude material using the bicinchonininc acid assay (MicroBCA, Pierce) in 96-well format using a BSA standard in artificial seawater, with absorbance values measured at $562 \mathrm{~nm}$. 
Absence of carbohydrates was confirmed by the phenol-sulfuric acid assay using a D-glucose standard in artificial seawater, with absorbance measured at $480 \mathrm{~nm}$. Semi-quantitative analysis of the presence of trace metals in the crude struvite was performed using SEM-EDS (FEI Quanta 3D FEG SEM with an Apollo 40 EDAX EDS detector). XRD measurements of the crude struvite crystals was performed using Bruker D8 X-ray diffractometer using 10-90 degree scans with steps of 0.02 degrees.

\subsubsection{Lab-scale spectrophotometric monitoring and cytometry}

For lab-scale growth assays, chlorophyll and near-IR optical densities (OD) were collected by the MC1000 multicultivator apparatus at 10 minute intervals during each assay. The spectrophotometric data was despiked to correct for refractive artifacts resulting from aeration bubbles by adapting a method previously described for correcting noise imparted on velocimeter data in bubbly flow (Mori et al., 2007). The data was then used to generate growth curves for comparing yields from the various media formulations. At various time points during the algal growth phase, aliquots of the cultures were serially diluted and dark-adapted for subsequent hemacytometry, UV-VIS spectrophotometry, and flow cytometry. This approach allowed determination of cell-counts from the spectrophotometric data by crosscorrelation with hemacytometry. Flow cytometry (Accuri C6, forward scatter cutoff $=100$, flow rate $=35 \mu \mathrm{L} / \mathrm{min}$, sheath diameter $=16 \mu \mathrm{m}$ ) was performed to evaluate cell-size and per-cell chlorophyll fluorescence. Calibration of the forward scatter detector channel was performed using the following sizes of fluorescent polystyrene beads (FluoSpheres, Invitrogen, USA) suspended in double distilled filtered $(20 \mathrm{~nm}$, Whatman, USA) water: $2.0 \mu \mathrm{m}, 7.52 \mu \mathrm{m}, 9.7 \mu \mathrm{m}$, and $15.41 \mu \mathrm{m}$. Analysis of the data 
was performed using software provided by Accuri or by the FloJo software package (Tree Star, Inc.). The flow cytometry measurements were also cross-validated with hemacytometry in order to obtain accurate cell counts. Chlorophyll content was determined spectrophotometrically following methanol extraction according to an established method (Ritchie, 2008). Specifically, $3 \mathrm{~mL}$ analytical grade methanol (Sigma) was added to $10 \mathrm{mg}$ lyophilized biomass in a shatter-proof and sealable container. The samples were then heated to $60^{\circ} \mathrm{C}$ and briefly vortex mixed, followed by 6 cycles of freeze-thaw. Freeze-thaw cycles were performed by alternating between liquid $\mathrm{N}_{2}$ and $60^{\circ} \mathrm{C}$ sonication baths upon visual inspection of solid-liquid phase change behavior, with brief vortex mixing between each transition. The cell suspensions were then centrifuged (7500xg, 4 min, room temp.) and the supernatant retained for UV-VIS absorbance measurements. Absorbance values collected at $665 \mathrm{~nm}$ and $470 \mathrm{~nm}$ were subsequently used to determine the concentrations of chlorophyll as described previously.

\subsubsection{Monitoring of outdoor cultures}

Outdoor cultures were monitored 2 times daily for salinity, temperature and $\mathrm{pH}$ using a YSI Model 650 handheld meter attached to a YSI 600XL multiparameter sonder (YSI, Inc. Yellow Springs, OH). Cultures were monitored daily for AFDW, phosphorus (FIAlab 2600, FIAlab Instruments Inc, Bellevue, W) and ammonia (Bower \& Bidwell, 1978). Productivity values were tested for normality and equality of variance prior to ANOVA with R-Studio (V. 0.98.1091) to determine if significant differences exist. Significant differences were determined by the Tukey's HSD inequality with the experiment-wise error rate set at $\leq 0.05$. Site conditions were monitored 
continuously for solar radiation, rainfall, wind speed and air temperature using an onsite weather station which is part of the Texas AgriLife crop weather monitoring program (http://cwp.tamu.edu). Each raceway was also monitored continuously for water temperature by the weather station. The $\mathrm{pH}$ in each raceway was maintained at $~ 7.8$ using a PinPoint pH controller (American Marine Inc. Ridgefield, CT) and $\mathrm{CO}_{2}$ injection system. Carbon dioxide was added to each raceway through a ceramic air diffuser (Sweetwater, Apoka, FL).

\subsubsection{Analysis of $N$ and $P$ concentrations in algae biomass}

Determination of total nitrogen and phosphate uptake in algae biomass was performed by oxisolv (potassium persulfate, EMD Millipore) digestion (Nydahl, 1978) followed by colorimetric analysis. Specifically, algae biomass samples were lyophilized and resuspended in sterile filtered double distilled water to achieve $0.5 \%$ solids loading. The samples were then sealed and placed on a shaker incubator at $40^{\circ} \mathrm{C}, 325 \mathrm{rpm}$ for 4 hours, followed by agitation for 16 hours at room temperature. Freshly prepared aqueous oxisolv solutions $(50 \mathrm{mg} / \mathrm{mL})$ were then combined with the samples at a 1:1 volume ratio. The oxidation reaction was then performed in an autoclave $\left(121^{\circ} \mathrm{C}, 15 \mathrm{psi}, 30 \mathrm{mins}\right)$. After cooling, the samples were centrifuged and the supernatant collected for colorimetric analyses. The concentration of phosphate was obtained using the malachite green assay described in section 2.4 .1 with the addition of $25 \mathrm{mg} / \mathrm{mL}$ oxisolve to the phosphate standards. Total nitrogen in the biomass was determined from the concentration of nitrate using the Griess reaction kit (Promega, Inc), with $25 \mathrm{mg} / \mathrm{mL}$ oxisolv added to the sodium nitrate standard solutions. Briefly, $50 \mu \mathrm{L}$ of sample was combined with 50 
$\mu \mathrm{L}$ of $1 \%$ solution of sulfanilamide in $5 \%$ phosphoric acid in a multiwall plate and incubated at room temperature with protection from light for 10 minutes. Immediately following, $50 \mu \mathrm{L}$ of a $0.1 \%$ solution of $\mathrm{N}$-1-napthylenediamine dihydrochloride in water was added to the sample wells and incubated at room temperature with protection from light for an additional 10 minutes, and the absorbance measured at 540nm.

\section{Results and Discussion}

Among the major challenges for achieving sustainable and cost-competitive biofuels and biobased commodities from microalgae, including means for low cost means harvesting, dewatering, and product recovery is the ability to effectively recycle the major N/P nutrients. Phosphate in particular is a non-renewable resource, and deemed "life's bottlekneck" by the renowned biochemist and author Isaac Asimov. The goal of this study was to investigate the potential for using struvite $\left(\mathrm{NH}_{4} \mathrm{MgPO}_{4}\right)$ for culture of microalgae. Struvite commonly forms as a problematic precipitate in wastewater treatment systems where sufficient quantities of soluble phosphate, ammonia, and magnesium are present at near neutral $\mathrm{pH}$. Based on this phenomenon, struvite is an attractive candidate for recapturing remineralized nitrogen and phosphorus from biomass processing if it can subsequently be used for high productivity algal culture. Although supplemental nitrogen would be required to achieve the stoichiometric ratios of nitrogen of phosphorus for microalgae, biomass processing with theoretical yield of capture of phosphate in the form of struvite would provide quantitative recycling of this strategic resource. 


\subsection{Chemical analysis of struvite}

Comparison of the chemical properties of reagent grade struvite (Sigma Aldrich) and wastewater stone ("crude struvite") samples obtained from a bovine concentrated animal feeding operation was performed. Following drying, $\left(105^{\circ} \mathrm{C}, 4\right.$ hrs) elemental analysis of the samples indicated the presence of $44.04 \%$ and 42.64\% (by mass) $\mathrm{H}_{2} \mathrm{O}$ equivalents for the pure and crude samples, respectively, consistent with the hexahydate form of the mineral. The total nitrogen was 3.63\% (crude) and 5.72\% (pure), phosphorus was 6.37\% (crude) and 12.62\% (pure), and magnesium was $3.47 \%$ (crude) and $9.90 \%$ (pure). Total carbon in the crude struvite was found to be $3.81 \%$, however, there was no indication of soluble protein or carbohydrate materials that may have otherwise contributed to heterotrophic growth of the microalgae. These data suggest that the elemental carbon that was detected was likely from carbonate salts (e.g. calcium carbonate and bicarbonate) related to the hardness of the source waters. Masses of pure and crude struvite equivalent to the saturation quantity of the pure mineral in artificial seawater yielded $0.206 \mathrm{mM}$ and $0.087 \mathrm{mM}$ soluble phosphate, respectively. Furthermore, masses of pure and crude struvite equivalent to the saturation quantity of the pure mineral in artificial seawater yielded $0.386 \mathrm{mM}$ and $0.227 \mathrm{mM}$ soluble ammonium, respectively. SEM-EDS analysis of the crude struvite samples indicated the presence of significant quantities of $\mathrm{Si}, \mathrm{Fe}, \mathrm{K}, \mathrm{Ca}, \mathrm{Al}, \mathrm{S}, \mathrm{Cl}$, and $\mathrm{Ti}$ (see $\mathrm{S} 2$ ); additional trace metals, including $\mathrm{Cr}, \mathrm{Mn}, \mathrm{Cu}, \mathrm{Ni}, \mathrm{V}$, and $\mathrm{Zn}$ were below the limit of detection. XRD measurements confirmed the presence of the struvite mineral lattice in the material (orthorhombic space group (Pmn2(1)): repeat unit lengths of $\mathrm{a}=6.945, \mathrm{~b}=11.208$, 
$c=6.1355$ ) (see S3); other magnesium phosphates, including apatite, phosphate apatites, dittmarite, collinsite, and baricite were not detected. However, the spectra confirm the previously reported hemimorphic nature of crude struvite crystal (Abbona \& Boistelle, 1979). These characterization data indicate that the wastewater stone used for our algae growth trials was composed of $\sim 48 \%$ struvite with a solubility coefficient, $K_{\mathrm{sp}} \sim 2 \times 10^{-14}$, corresponding to $\sim 90 \%$ of values reported at similar temperatures but significantly lower osmotic strengths than those reported in a recent study of the thermodynamic solubility of struvite (Bhuiyan et al., 2007), and consistent with the commonly cited literature on the physico-chemical properties of struvite (Snoeyink \& Jenkins, 1980; Taylor et al., 1963). Based on these data, the non-struvite fraction of the wastewater stone is likely composed primarily of non-biogenic silica, alumina, and various other metal oxides commonly observed in silt.

\subsection{Algae productivity}

In order to evaluate the potential for replacing conventional algae nutrients with struvite, lab-based and outdoor pilot scale growth trials were conducted using two promising marine microalgae production species, Nannochloropsis salina and Phaeodactylum tricornutum. Yields from batch culture of the two algae species were compared with established enriched natural seawater formulations in the outdoor pilot scale trials and enriched artificial seawater medium in the lab trials, with similar trends observed in the two cultivation systems. In the outdoor phosphorus replacement trials the ability of struvite to replace phosphorus was assessed using 1) monocultures of $N$. salina (CCMP 1776), 2) monocultures of $P$. 
tricornutum (local isolate), 3) mixed cultures of $N$. salina and P. tricornutum (under seasonal conditions favoring $N$. salina growth; mean PM water temperature of $30.5 \pm 2.4^{\circ} \mathrm{C}$ ), and 4 ) mixed cultures of N. salina and P. tricornutum (under seasonal conditions favoring $P$. tricornutum growth; mean PM water temperature of $13 \pm 7^{\circ} \mathrm{C}$ ). Daily maximum and cumulative biomass productivities (g AFDW $/ \mathrm{m}^{2} /$ day) of outdoor raceway trials cultivated with phosphorus replacement (\% of control), labeled as "P-replacement", using commercial struvite is presented in Fig 1A. Daily maximum and cumulative biomass productivities of trials cultivated with nitrogen replacement (\% of control), e.g. N:P 1:1 based on the stoichiometric ratio of $\mathrm{N}$ and $\mathrm{P}$ in struvite and labeled as "N:P replacement", is presented in Fig 1B. For N:P replacement, the P levels exceed those in the control. There were few significant differences in biomass productivity between the treatments during the course of the four phosphorus replacement trials. The data from these trials suggests struvite was able to completely replace phosphorus in the nutrient mix without any adverse effect on the average biomass yield of mono- and mixed cultures of $N$. salina and $P$. tricornutum. For the nitrogen replacement regime (N:P 1:1), there were several instances of increased biomass productivity by the use of struvite as a source for both $\mathrm{N}$ and P. For N. salina in particular, use of struvite as a major nutrient replacement resulted in a significant increase in cumulative productivity versus controls for summer monoculture cultivation and for winter co-culture. Analysis of the species composition of the co-cultures (N:P replacement "winter" and "spring") on a cell count basis revealed that $N$. salina was the dominant algae species in both of the control cultures (44.4:1 in "spring" and 56.5:1 in "winter). In the 
experimental struvite-based cultures, however, the species dominance was either greatly reduced (6.8-10.3:1 in "spring") or eliminated (0.68-2.6:1 in "winter"), without detrimental impact on yield. In order to assess the potential impact of "slow nutrient release" of the N/P from struvite related to solvation kinetics and nutrient uptake by the algae cells, the assays were extended well beyond the anticipated log-phase growth regime. The extended production data suggests the "slow release" of the struvite nutrients did not impact microalgae growth or raceway contamination based on microscopic evaluation. In the lab trials, however, late stage growth of both $N$. salina and P. tricornutum was more robust using crude struvite equivalents (from wastewater stone) in place of the established nutrient formulation for L1 medium (Berges et al., 2001). The fact that this effect was not significant for the growth trials that utilized pure struvite may relate to the presence of potentially limiting trace metals present in the crude struvite source. 

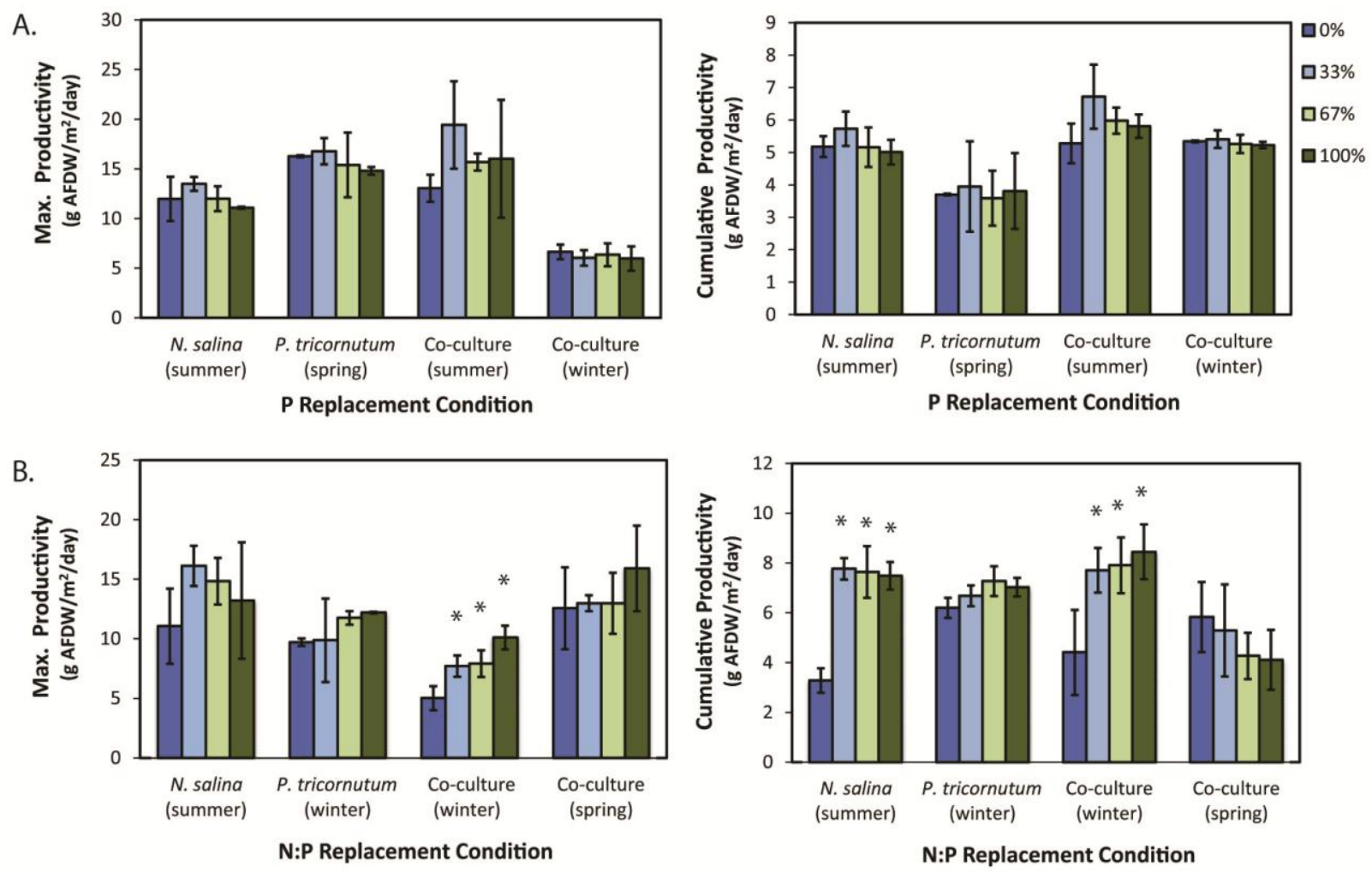

Figure 1. Maximum and cumulative ash-free biomass productivity (dry weight) of N. salina, P. tricornutum, and co-cultures cultures obtained from 15 day outdoor raceway growth trials performed from October 2013 through April 2015 in Corpus Christi, TX. Nutrient conditions depicted in (A) correspond to various phosphate replacement regimen by struvite according to the Redfield ratio $(16: 1 \mathrm{~N}: \mathrm{P})$. Nutrient conditions depicted in (B) correspond to various nitrogen replacement regimen by struvite, resulting in 1:1 N:P, e.g. excess phosphate. Data labeled with an asterisk indicates significant difference from the control medium formation. N. salina P replacement "summer" cultures were terminated Oct 14, 2013; P. tricornutum P replacement "spring" cultures were terminated April 9, 2015; co- 
culture P replacement "summer" cultures were terminated June 14, 2014; co-culture P replacement "winter" cultures were terminated Feb 7, 2014;

N. salina N:P replacement "summer" cultures were terminated Oct 15, 2014; $P$.

tricornutum N:P replacement "winter" cultures were terminated Feb 7, 2015; coculture N:P replacement "winter" cultures were terminated Feb 26, 2015; co-culture N:P replacement "spring" cultures were terminated April 8, 2015. See Table 1 for details including solar radiation intensity, temperature, precipitation, wind speed, and culture $\mathrm{pH}$ and salinity.

Table 1. Environmental data from pilot-scale outdoor raceway cultures and cultivator parameters used in the lab-scale cultures

\begin{tabular}{|c|c|c|c|c|c|c|c|c|}
\hline \multirow[b]{2}{*}{ Species Identifier, Replacement } & \multicolumn{2}{|c|}{ Medium Temp. $\left({ }^{\circ} \mathrm{C}\right)$} & \multirow{2}{*}{$\begin{array}{c}\text { Salinity } \\
\text { (ppt) }\end{array}$} & \multirow[t]{2}{*}{$\mathrm{pH}$} & \multirow{2}{*}{$\begin{array}{l}\text { Solar Radiation } \\
\text { (kCal/cm2/day) }\end{array}$} & \multirow{2}{*}{$\begin{array}{c}\text { Air Temp. } \\
\left({ }^{\circ} \mathrm{F}\right)\end{array}$} & \multirow{2}{*}{\begin{tabular}{|c|}
$\begin{array}{c}\text { Tot. Precipitation } \\
\text { (inches) }\end{array}$ \\
\end{tabular}} & \multirow{2}{*}{$\begin{array}{c}\text { Wind Speed } \\
(\mathrm{mph})\end{array}$} \\
\hline & A.M. & P.M. & & & & & & \\
\hline N. salina, $\mathrm{P}$ & $25.1 \pm 0.4$ & $29.4 \pm 1.7$ & $26.5 \pm 5.1$ & $7.4 \pm 0.4$ & $363.9 \pm 124.8$ & $83.0 \pm 6.2$ & 6.47 & $6.3 \pm 1.6$ \\
\hline P. triconutum , $\mathrm{P}$ & $16.2 \pm 5.5$ & $24.8 \pm 4.4$ & $33.4 \pm 1.0$ & $7.4 \pm 0.3$ & $504.9 \pm 137.1$ & $70.4 \pm 8.9$ & 0.13 & $6.2 \pm 2.3$ \\
\hline N. salina \& $P$. triconutum, $\mathrm{P}$ & $23.2 \pm 4.0$ & $30.5 \pm 2.4$ & $34.0 \pm 2.3$ & $7.5 \pm 0.4$ & $455.1 \pm 71.0$ & $80.8 \pm 9.5$ & 2.12 & $5.1 \pm 1.1$ \\
\hline N. salina \& $P$. triconutum, $\mathrm{P}$ & $10.9 \pm 5.8$ & $12.9 \pm 7.0$ & $33.5 \pm 1.1$ & $7.5 \pm 0.1$ & $215.6 \pm 113.5$ & $52.6 \pm 13.3$ & 0.02 & $7.3 \pm 2.9$ \\
\hline N. salina \& $P$. triconutum, $\mathrm{N}: \mathrm{P}$ & $11.6 \pm 4.3$ & $16.8 \pm 5.1$ & $31.9 \pm 0.9$ & $7.5 \pm 0.1$ & $316.9 \pm 185.3$ & $56.9 \pm 9.2$ & 0.85 & $7.2 \pm 2.5$ \\
\hline N. salina \& $P$. triconutum $, \mathrm{N}: \mathrm{P}$ & $21.2 \pm 1.7$ & $24.97 \pm 2.7$ & $24.8 \pm 3.9$ & $7.5 \pm 0.3$ & $279.9 \pm 110.2$ & $73.9 \pm 2.3$ & 6.20 & $5.1 \pm 1.3$ \\
\hline N. salina, $\mathrm{N}: \mathrm{P}$ & $19.0 \pm 3.0$ & $25.6 \pm 2.8$ & $29.0 \pm 5.2$ & $7.7 \pm 0.2$ & $369.8 \pm 76.8$ & $75.2 \pm 8.8$ & 3.22 & $5.5 \pm 1.8$ \\
\hline P. triconutum, $\mathrm{N}: \mathrm{P}$ & $11.28 \pm 5.5$ & $17.0 \pm 7.0$ & $30.3 \pm 0.7$ & $7.56 \pm 0.1$ & $288.4 \pm 154.8$ & $56.9 \pm 10.8$ & 0.05 & $7.0 \pm 2.3$ \\
\hline
\end{tabular}

Lab-scale cultivation parameters

Culture tube diameter $=25 \mathrm{~mm}$

Culture tube length $=2030 \mathrm{~mm}$

Culture volume $=90 \mathrm{~mL}$

Headspace $=10 \mathrm{~mL}$

Water bath volume $=4 \mathrm{~L}$

Light source $=$ white strip LED aligned $12.5 \mathrm{~mm}$ from long axis edge of culture tube

\section{$3.3 \mathrm{~N} / \mathrm{P}$ nutrient uptake}

Assessment of nutrient uptake time courses and the associated N:P ratios for the two algae strains indicate some potentially impactful differences for the different major nutrient sources. Biomass samples collected at regular intervals during the extended outdoor cultivation trials were analyzed to determine the 
uptake of nitrogen and phosphate under various P-replacement regimes using struvite. Time course data showing the total $\mathrm{N}$ and phosphate concentrations of the biomass for both microalgae strains is presented in Fig 2. For P. tricornutum, the maximum phosphate accumulation occurs in control medium after day 8 until the end of the growth trial; in samples where struvite was used as a replacement for $\mathrm{N} / \mathrm{P}$, maximum phosphate accumulation occurs after day 8 but decreases by day 15 ; this effect is present in both the controls and experimental conditions, however the effect is more pronounced with increasing P-replacement by struvite. For N. salina, the maximum phosphate accumulation also occurs in control medium between day 4 and day 15 of the trial; in samples where struvite was used as a replacement for N/P, phosphate accumulation remains largely static during the extended growth trial. For both P. tricornutum and N. salina, the total nitrogen accumulated in the biomass reached a peak between day 4 and day 12 of the trial, with some indication of N-enrichment in samples with nutrient replacement by struvite. For both $P$. tricornutum and $N$. salina, the $\mathrm{N}: \mathrm{P}$ ratios roughly followed the $\mathrm{N}$-accumulation trends. However, samples with higher levels of nutrient replacement by struvite had the highest $\mathrm{N}: \mathrm{P}$, albeit at different growth intervals. For $P$. tricornutum, $\mathrm{N}: \mathrm{P}$ was consistently higher in the late growth stages (following day 12) in struvitecontaining samples than in controls. In this case, the average N:P was 17-24:1 in samples with $100 \%$ phosphorus replacement by struvite and 6-8:1 in control medium at day 12 and day 15. For N. salina, N:P was consistently higher in the midgrowth stages (day 4 through day 8) in struvite-containing samples than in controls. 
In this case, the average $\mathrm{N}: \mathrm{P}$ was $44-47: 1$ in samples with $100 \%$ phosphorus replacement by struvite and 10-26:1 in control medium at day 4 and day 8 .

The trend that emerged for both algae species was the tendency to accumulate less phosphate and more nitrogen with increasing replacement of conventional major nutrient sources by struvite. This effect led to substantially higher N:P ratios in the biomass in certain growth stages for algae cultivated on struvite compared to L1 medium. For $P$. tricornutum the effect is evident only very late in the extended growth trial, whereas for N. salina, the effect is evident in midto late-log phase. High levels of phosphorus accumulation in the biomass using control medium never resulted in increased biomass productivity. This effect suggest that replacement of more soluble forms of phosphate common in standard media formulations with struvite may prevent luxury uptake of phosphorus (Powell et al., 2011). It has been previously observed that $P$. tricornutum in particular is very efficient in depleting available phosphorus in algae cultivation media (Ansell et al., 1964; Kuenzler \& Ketchum, 1962). Although this is desirable for purposes of wastewater remediation, more efficient phosphorus resource utilization could have a dramatic benefit for reducing the overall nutrient costs incurred for commercial culture of algae biomass (Liu et al., 2013). The fact that nitrogen resource utilization efficiency appears to have increased in struvite-based media suggests that the protein content of the biomass is elevated compared to that grown in control medium, as proteins are the dominant nitrogen sink $(80-90 \%$ of biological N) in algae (Barsanti \& Gualtieri, 2014). 

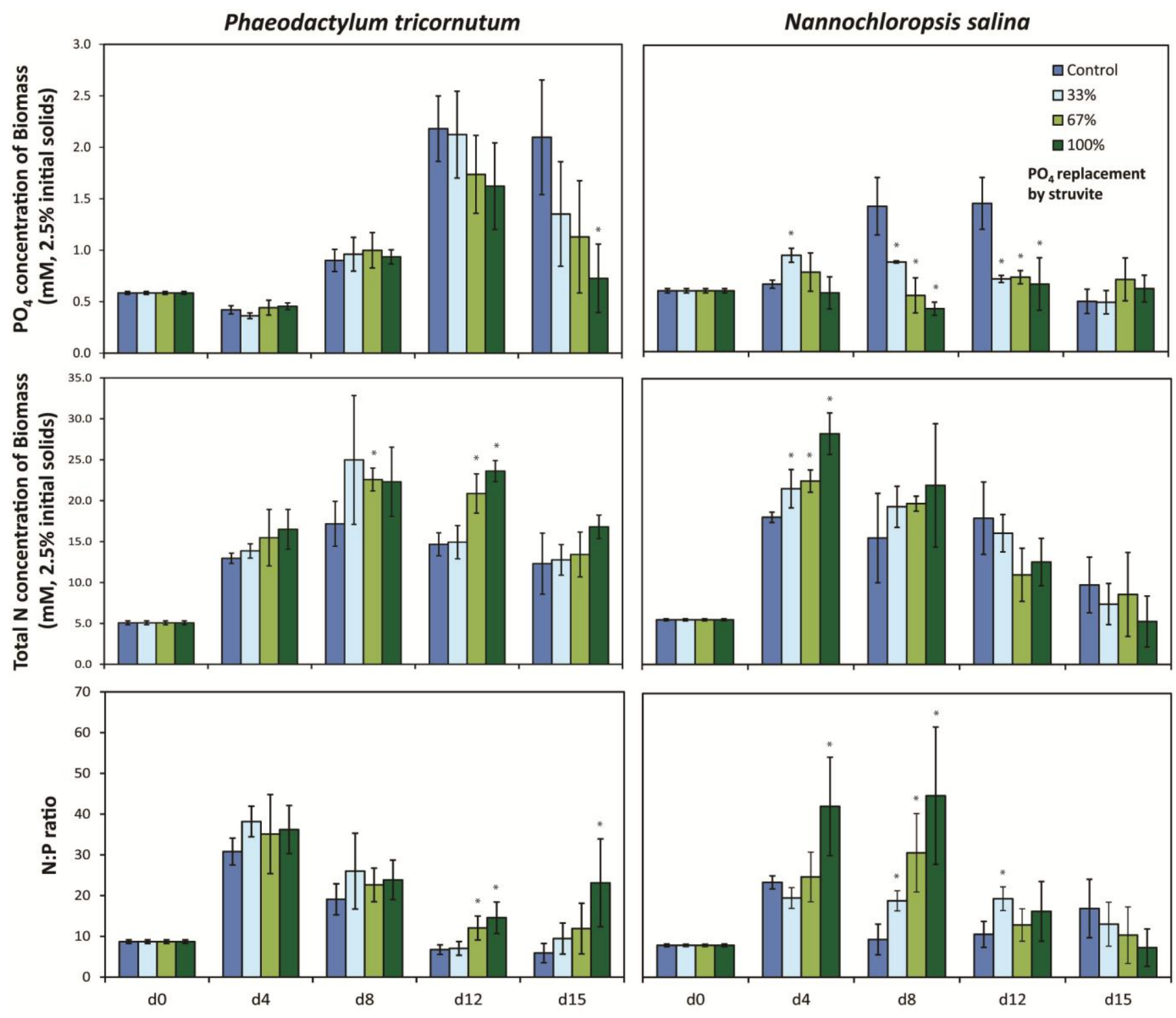

Days in batch culture

Figure 2. Concentrations of major nutrients in harvested P. tricornutum and $N$.

salina biomass cultivated with struvite in outdoor raceways. Top panels: total cellular phosphate concentration versus time in batch culture. Middle panels: total cellular nitrogen versus time in batch culture. Bottom panels: Ratio of nitrogen and phosphorus versus time in batch culture. Data labeled with an asterisk indicates significant difference from the control medium formation. 


\subsection{Physiological parameters of algae grown on struvite}

Based on the expectation of phenotypic and biochemical variations under variable nutrient regimes (Geider \& La Roche, 2002), basic physiological parameters and the pigment content of the biomass were assessed to establish the potential of using struvite for algae culture for biofuel and bioproduct applications. In addition to biomass yield, two key physiological parameters of interest were monitored based on cultivation of N. salina and P. tricornutum using struvite as a nutrient source. These parameters included the pigment yield as indicated by chlorophyll fluorescence and the effective mean cell diameter, each measured by flow cytometry. Finally, correlation of the in situ optical density values at $800 \mathrm{~nm}$ (OD800) to cell counts obtained by hemacytometry allowed accurate determination of cell counts from the spectrophotometric method. For N. salina, cell counts corresponding to $2.362 \times 10^{7}$ per OD800 $\left(-2.328 \times 10^{6}\right.$ intercept $)$ were obtained; for $P$. tricornutum, cell counts corresponding to $1.610 \times 107$ per OD800 $\left(-1.080 \times 10^{6}\right.$ intercept) were obtained, indicating a cell count per OD800 ratio of 1.467 of Nannochloropsis compared to P. tricornutum for OD800 values $<2$. Flow cytometry data indicated an average forward scatter ratio of 0.868 of $N$. salina relative to $P$. tricornutum, corresponding to a relative cell volume of 0.71 . Combining the relative cell count per OD800 and normalized by the relative cell volume gives approximately unity (1.04), consistent with our previous measurements for biomass estimation from near IR spectrophotometry of microalgae of varying composition (Davis et al., 2015). 
Previous studies suggest that differences in the nitrogen source can have substantial impacts on the growth rate of algae (Ludwig, 1938). Figure 3 depicts the biomass productivity, effective mean cell diameter, and the chlorophyll A concentration per cell normalized to cell volume $\left(\mathrm{V}_{\mathrm{b}}\right)$ for $N$. salina and P. tricornutum cultured using crude and purified struvite for full phosphorus replacement as compared to control (L1) cultures. The total biomass productivity in these studies was found to be either insignificantly different or elevated for the struvite-based cultures, in agreement with the results of the outdoor raceway growth trials. Furthermore, cultures containing crude struvite for $100 \%$ phosphorus replacement but lacking the addition of trace metals (see S1) were found to be equally productive as cultures grown on L1 medium, suggesting that crude struvite not only provides major N/P nutrients, but also fulfills the trace metals requirement for these algae strains. For some algae species, especially fresh water variants, the presence of increased loadings of trace metals may be deleterious. In a previous study, the authors concluded that trace metals are a dominant factor in physiological changes in algal cells (Cakmak et al., 2014). Here we observed that the effective mean diameter of the algae cells was larger for both algae strains when cultivated in L1 versus crude struvite at stationary phase, but no significant size differences were observed between the L1 and purified struvite cultures, potentially resulting from the presence of additional trace metals in the crude material. The mean ChlA pigment concentration per cell (normalized to mean cell biovolume) was also found to be elevated in struvite-based medium compared to L1 for both strains; significantly elevated pigment concentrations were detected in both the purified 
and crude struvite media formulations for N. salina, but only in the crude struvite formulation for P. tricornutum at stationary phase. Overall reduction in per cell pigment levels were observed for all strains and media at stationary phase (day 8), however the effect was more exaggerated in L1 medium. Therefore, cultivation of algae using struvite, especially in crude form, was found to have a beneficial role for increasing pigment accumulation or minimizing pigment loss resulting from nutrient depletion stress in the algae cells. 


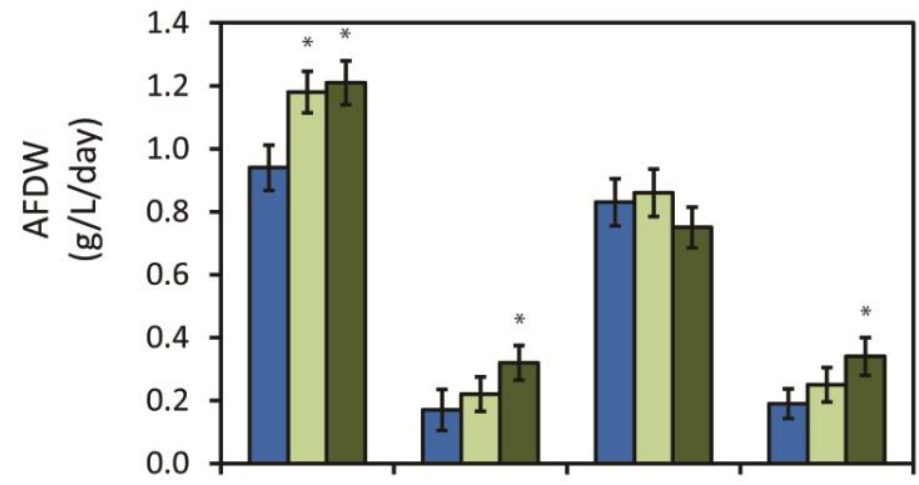

\author{
口L1 medium \\ $\square$ Purified struvite \\ $\square$ Crude struvite
}
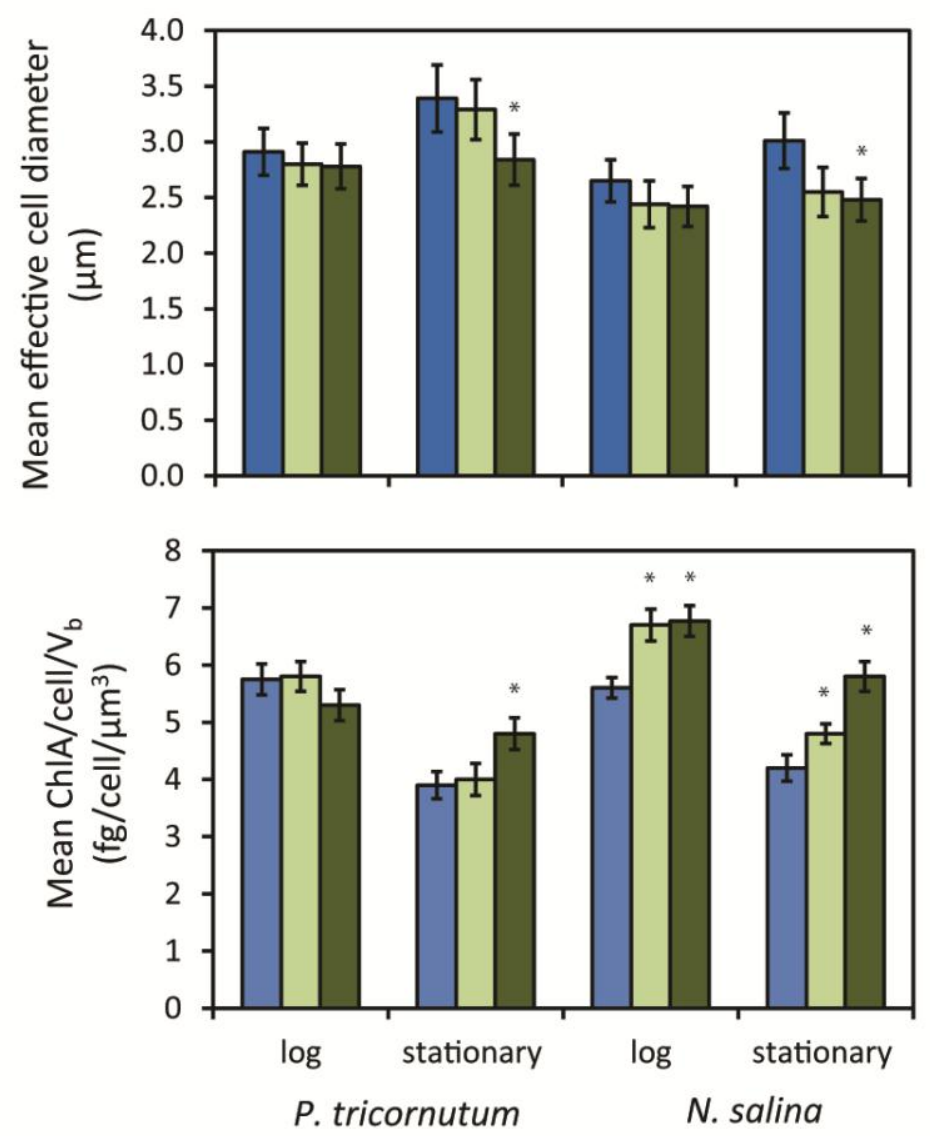

Figure 3. Productivity and physiological parameters of lab cultures cultivated with the full phosphate requirement provided by control medium (L1), purified struvite, and crude struvite. Biomass yield, in terms of ash-free dry weight (AFDW), mean effective cell diameter, and mean chlorophyll concentration per cell per unit biovolume $\left(\mathrm{V}_{\mathrm{b}}\right)$ (estimated from flow cytometry) are depicted for $N$. salina and $P$. 
tricornutum monocultures for day three of cultivation, representing log-phase growth, and day eight of cultivation, representing stationary phase. Data labeled with an asterisk indicates significant difference from the control medium formation.

A potential concern for utilization of struvite as a major nutrient source for algae cultivation is the apparent mismatch between the stoichiometric equivalents of $\mathrm{N}$ and $\mathrm{P}$ in struvite versus the typical, Redfield ratio-based culture medium formulations (Geider \& La Roche, 2002). In this work, we either supplemented the struvite growth medium with sodium nitrate to achieve total $\mathrm{N}$ equivalency between the control and experimental media or struvite was applied at concentrations required to achieve the full $\mathrm{N}$-requirement (resulting in N:P 1:1, e.g. excess P). The fact that complete replacement of the phosphate requirement by struvite resulted in significantly elevated $\mathrm{N}: \mathrm{P}$ in the biomass suggest that significant deviations from the Redfield ratio may be maintained and do not hinder high biomass productivities. This is corroborated by our N:P replacement data and previous observations that relative to the standard Redfield ratio, decreased N:P ratios are supportive of algal blooms in ecological nutrient cycling (Arrigo, 2005). Furthermore, in a recent study on cultivation of Nannochloropsis sp., the authors observed an increase in biomass productivity of up to $\sim 47 \%$ for N:P of 3:1 relative to 20:1(Encarnacao et al., 2012). Together these data suggest that although phosphorus replacement is likely most economical application for struvite in algae culture, there appears to be little biological necessity to adhere to canonical nutrient ratios in its use. 


\section{Conclusion}

The results of this study demonstrate growth of mono- and co-cultures of Nannochloropsis salina and Phaeodactylum tricornutum using struvite as a replacement for the major nutrients, nitrogen and phosphorus. Trends observed in lab cultures grown on synthetic media were found to have strong predictive value for trends observed in outdoor culture in pilot-scale raceway systems. The results suggest that struvite is a suitable replacement for conventional $\mathrm{N}$ and $\mathrm{P}$ sources, and that struvite-based medium can outperform conventional media for biomass productivity, pigment accumulation, nutrient utilization efficiency, and may serve as an effective mineral form for nutrient recycling from biomass processing.

\section{Acknowledgements}

Sandia National Laboratories is a multi-program laboratory managed and operated by Sandia Corporation, a wholly owned subsidiary of Lockheed Martin Corporation, for the U.S. Department of Energy's National Nuclear Security Administration under contract DE-AC04-94AL85000. Laboratory scale culture experiments and analyses at Sandia National Laboratories were supported by Laboratory Directed Research and Development program. Pilot scale growth trials and analyses at Texas Agrilife were supported by the BioEnergy Technology Office, U.S. Department of Energy under Award 9.1.1.3_DE-EE0005995. 


\section{References}

1. Abbona, F., Boistelle, R. 1979. Growth Morphology and Crystal Habit of Struvite Crystals (Mgnh4po4.6h2o). Journal of Crystal Growth, 46(3), 339-354.

2. Ansell, A.D., Coughlan, J., Lander, K.F., Loosmore, F.A. 1964. Studies on the mass culture of Phaeodactylum. IV. Production and nutrient utilization in outdoor mass culture. Limnol. Oceanogr., 9(3), 334-342.

3. Arrigo, K.R. 2005. Marine microorganisms and global nutirent cycles. Nature, 437, 349-355.

4. Barsanti, L., Gualtieri, P. 2014. Algae: Anatomy, Biochemistry, and Biotechnology, Second Edition. CRC Press, Boca Raton, FL.

5. Berges, J.A., Franklin, D.J., Harrison, P.J. 2001. Evolution of an artificial seawater medium: Improvements in enriched seawater, artificial water over the last two decades. Journal of Phycology, 37(6), 1138-1145.

6. Bhuiyan, M.I., Mavinic, D.S., Beckie, R.D. 2007. A solubility and thermodynamic study of struvite. Environ Technol., 28(9), 1015-26.

7. Bhuiyan, M.I., Mavinic, D.S., Koch, F.A. 2008. Phosphorus recovery from wastewater through struvite formation in fluidized bed reactors: a sustainable approach. Water Sci Technol, 57(2), 175-81.

8. Bower, C.E., Bidwell, J.P. 1978. Ionization of ammonia in seawater - Effects of temperature, $\mathrm{pH}$, and salinity. Journal of Fisheries Research Board of Canada, 35, 1012-1016.

9. Buluswar, S., Friedman, Z., Mehta, P., Mitra, S., Sathre, R. 2014. 50 Breakthroughs: Critical scientific and technological advances needed for sustainable global development. in: LIGTT, LBNL Institute for Globally Transformative Technologies. Berkeley, CA, USA.

10. Cai, T., Park, S.Y., Li, Y. 2013. Nutrient recovery from wastewater stream by microalgae: Status and prospects. Renewable \& Sustainable Energy Reviews, 19, 360-369.

11. Cakmak, Z.E., Olmez, T.T., Cakmak, T., Menemen, Y., Tekinay, T. 2014. Induction of triacylglycerol production in Chlamydomonas reinhardtii: Comparative analysis of different element regimes. Bioresour Technol, 155, 379-387.

12. Davis, R.W., Carvalho, B.J., Jones, H.D.T., Singh, S. 2015. The role of photo-osmotic adaptation in semi-continuous culture and lipid release from Dunaliella viridis. Journal of Applied Phycology, 27, 109-123.

13. Encarnacao, T., Burrows, H.D., Pais, A.C., Campos, M.G., Kremer, A. 2012. Effect of $\mathrm{N}$ and $\mathrm{P}$ on the uptake of magnesium and iron and on the production of carotenoids and chlorophyll by the microalgae Nannochloropsis sp. Journal of Agricultural Science and Technology 2, 824-832.

14. Fattah, K.P. 2012. Assessing struvite formation potential at wastewater treatment plants. International Journal of Environmental Science and Development, 3(6), 548-552.

15. Geider, R.J., La Roche, J. 2002. Redfield revisited: variability of C:N:P in marine microalgae and its biochemical basis. European Journal of Phycology, 37, 1-17. 
16. Greenwell, H.C., Laurens, L.M., Shields, R.J., Lovitt, R.W., Flynn, K.J. 2010. Placing microalgae on the biofuels priority list: a review of the technological challenges. J Roy Soc Interf, 7(46), 703-26.

17. Klausmeier, C.A., Litchman, E., Daufresne, T., Levin, S.A. 2004. Optimal nitrogento-phosphorus stoichiometry of phytoplankton. Nature, 429, 171-174.

18. Kuenzler, E.J., Ketchum, B.H. 1962. Rate of phosphorus uptake by Phaeodactylum tricornutum. Bio. Bull., 123(1), 134-145.

19. Liu, X., Saydah, B., Eranki, P., Colosi, L.M., Mitchell, B.G., Rhodes, J., Clarens, A.F. 2013. Pilot-scale data provide enhanced estimates of the life cycle energy and emissions profile of algae biofuels produced via hydrothermal liquefaction. Bioresour Technol, 148, 163-171.

20. Lougheed, T. 2011. Phosphorus paradox: Scarcity and overabundance of a key nutrient. Environmental Health Perspectives, 119(5), A208-A213.

21. Ludwig, C.A. 1938. The availability of different form of nitrogen to a green alga. Journal of Botany, 25, 448-458.

22. Marti, N., Pastor, L., Bouzas, A., Ferrer, J., Seco, A. 2010. Phosphorus recovery by struvite crystallization in WWTPs: influence of the sludge treatment line operation. Water Research, 44(7), 2371-9.

23. Mori, N.T., Suzuki, T., Kakuno, S. 2007. Noise of acoustic Doppler velocimeter data in bubbly flow. Journal of Engineering Mechanics, 133(1), 122-125.

24. Neset, T.-S.N., Cordell, D. 2012. Global phosphorus scarcity: identifying synergies for a sustainable future. Journal of the Science of Food and Agriculture, 92(1), 2-6.

25. Nydahl, F. 1978. On the peroxodisulphate oxidation of total nitrogen in waters to nitrate. Water Research, 12, 1123-1130.

26. Pate, R., Klise, G., Wu, B. 2011. Resource demand implications for US algae biofuels production scale-up. Appl Energ, 88(10), 3377-3388.

27. Powell, N., Shilton, A., Pratt, S., Chisti, Y. 2011. Luxury uptake of phosphorus by microalgae in full-scale waste stabilisation ponds. Water Sci Technol, 63(4), 704-9.

28. Ritchie, R.J. 2008. Universal chlorophyll equations for estimating chlorophylls a, b, c, and d and total chlorophylls in natural assemblages of photosynthetic organisms using acetone, methanol, or ethanol solvents. Photosynthetica, 46, 115-126.

29. Sengupta, S. 2013. Macronutrient removal and recovery from tertiary treatment of wastewater. in: Novel Solutions to Water Pollution, (Eds.) S. Ahuja, K. Hristovski, Oxford University Press. Northamptonshire, G.B., pp. 167-187.

30. Smil, V. 2000. Phosphorus in the environment: Natural flows and human interferences. Annu Rev Energy Envinron, 25, 53-88.

31. Snoeyink, V.L., Jenkins, D. 1980. Water chemistry. Wiley, University of Michigan.

32. Taylor, A.W., Frazier, A.W., Gurney, E.L. 1963. Solubility product of magnesium ammonium. Trans. Faraday Soc., 59, 1580-1589.

33. Tchobangolous, G., Burton, F.L., Stensel, H.D. 2003. Wastewater Engineering: Treatment and Reuse. 4 ed. McGraw-Hill, New York, NY. 
34. Uysal, A., Yilmazel, Y.D., Demirer, G.N. 2010. The determination of fertilizer quality of the formed struvite from effluent of a sewage sludge anaerobic digester. Journal of Hazardous Material, 181(1-3), 248-54.

35. Zmora, O., Richmond, A. 2007. Microalgae for Aquaculture: Microalgae Production for Aquaculture. in: Handbood of Microalgal Culture: Biotechnology and Applied Phycology, (Ed.) A. Richmond, Vol. Blackwell Publishing Ltd. Oxford, UK. 

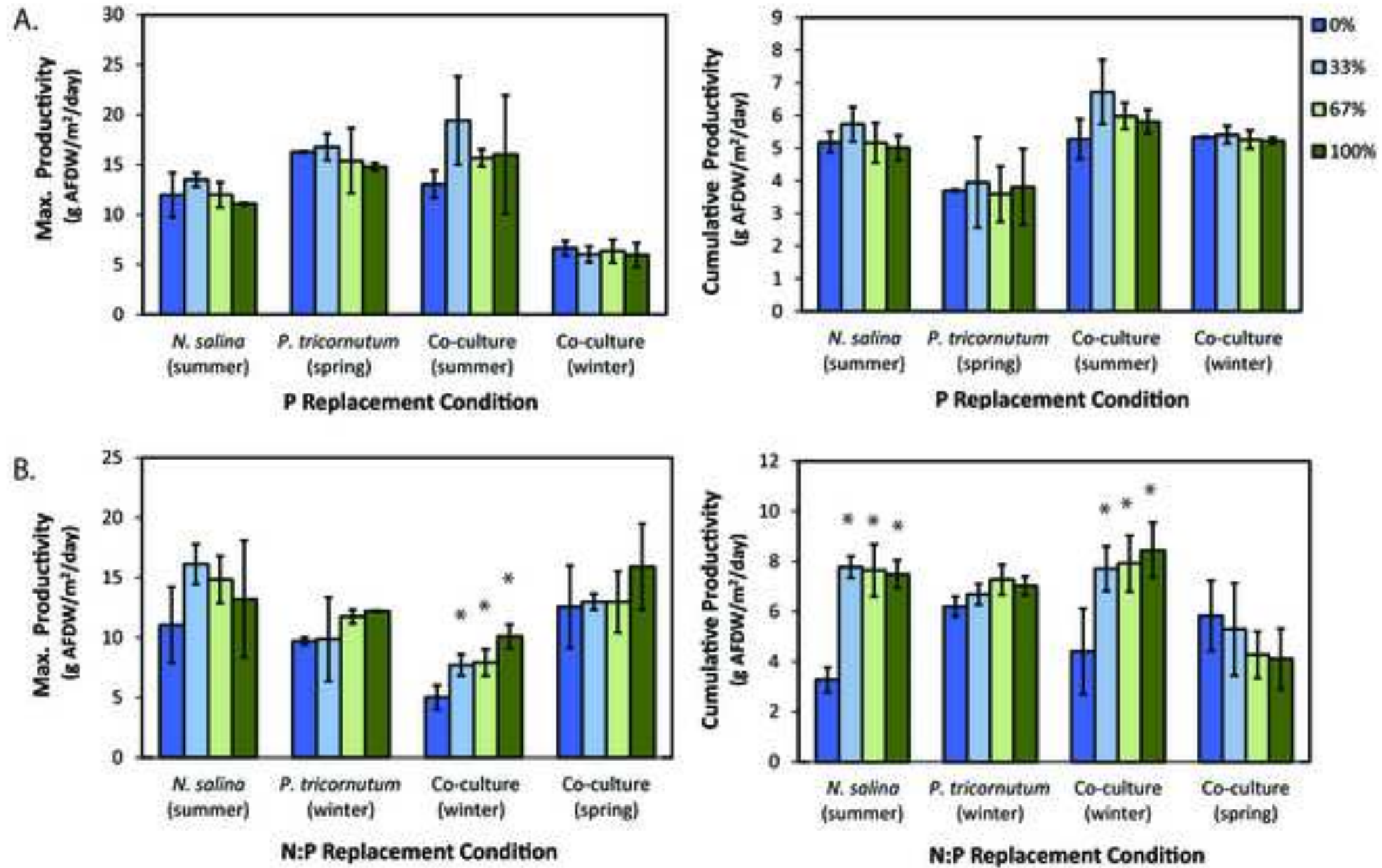

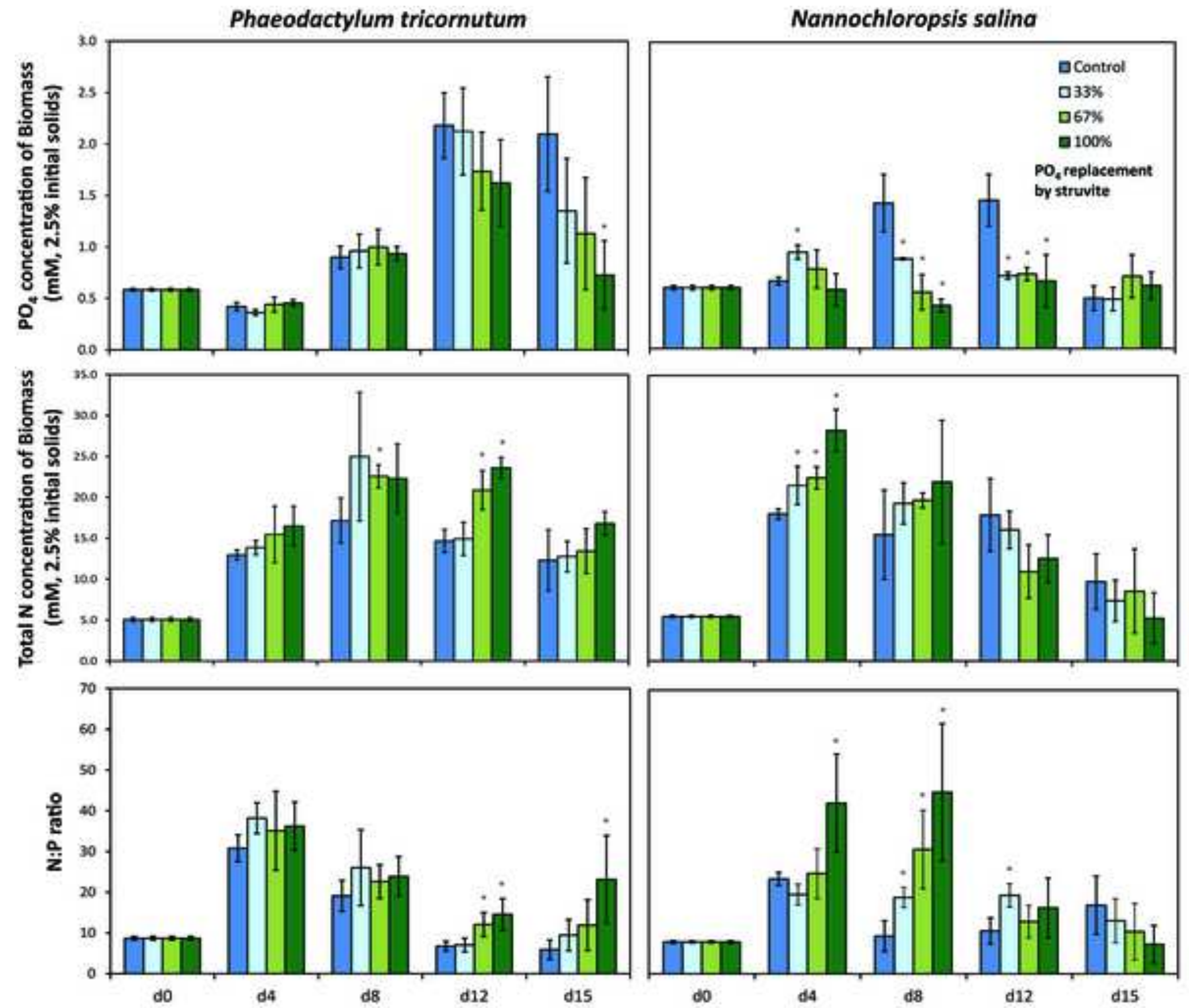

Days in batch culture 


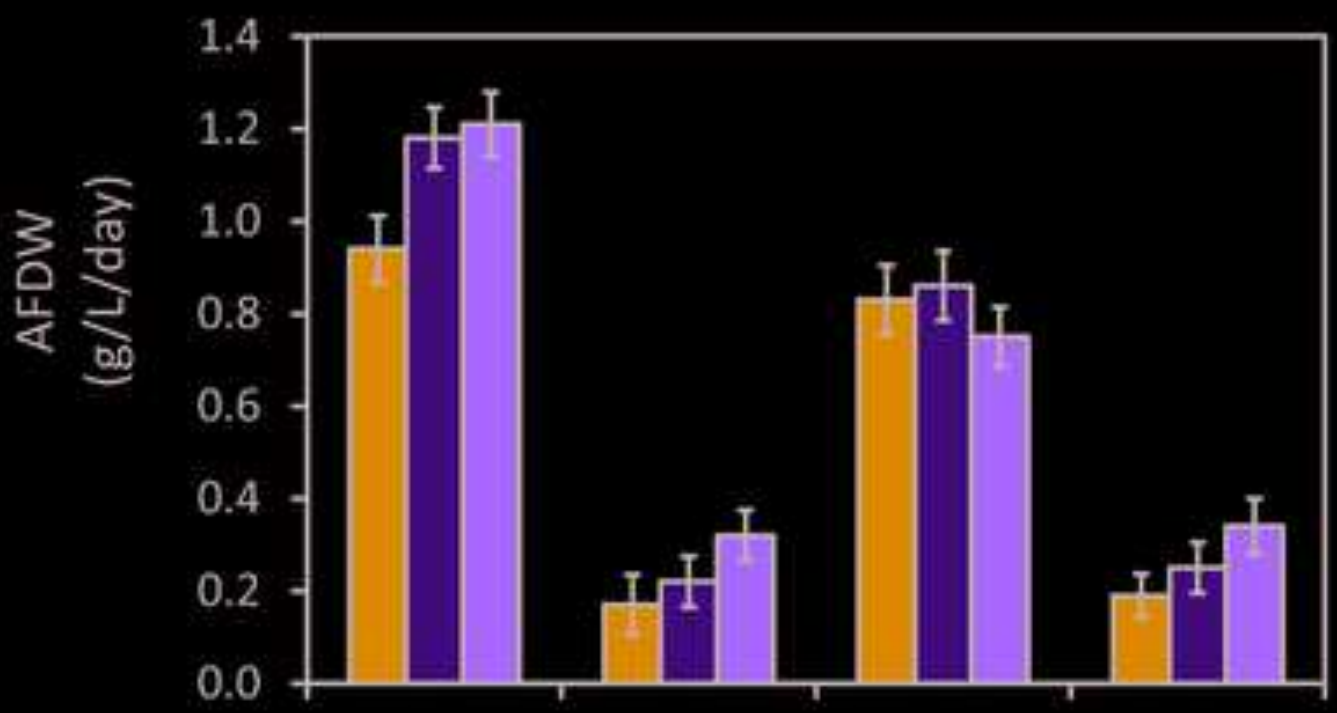

Q L1 medium

口Purified struvite

Q Crude struvite
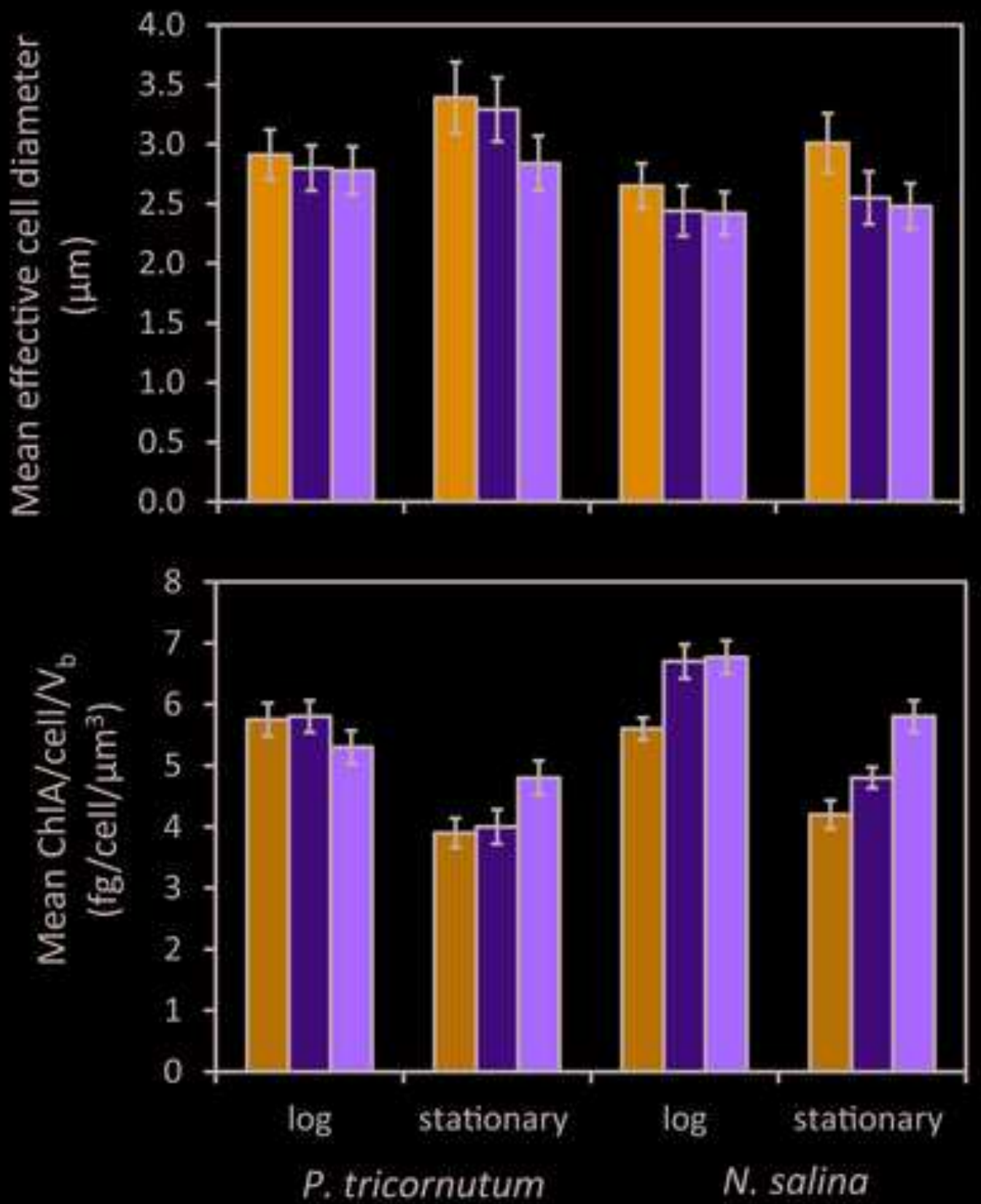

P. tricornutum

N. salina 
Pilot-scale cultivation parameters

\begin{tabular}{|c|c|c|c|c|}
\hline & \multicolumn{2}{|c|}{ Medium Temp. $\left({ }^{\circ} \mathbf{C}\right)$} & \multirow{2}{*}{$\begin{array}{c}\text { Salinity } \\
\text { (ppt) }\end{array}$} & pH \\
\hline Species Identifier, Replacement & A.M. & P.M. & $26.5 \pm 5.1$ & $7.4 \pm 0.4$ \\
\hline N. salina, P & $25.1 \pm 0.4$ & $29.4 \pm 1.7$ & 26.7 & $7.4 \pm 0.3$ \\
\hline P. triconutum, P & $16.2 \pm 5.5$ & $24.8 \pm 4.4$ & $33.4 \pm 1.0$ & $7.5 \pm 0.4$ \\
\hline N. salina \& P. triconutum, P & $23.2 \pm 4.0$ & $30.5 \pm 2.4$ & $34.0 \pm 2.3$ & $7.5 \pm 0.1$ \\
\hline N. salina \& P. triconutum, P & $10.9 \pm 5.8$ & $12.9 \pm 7.0$ & $33.5 \pm 1.1$ & $7.5 \pm 0.1$ \\
\hline N. salina \& P. triconutum , N:P & $11.6 \pm 4.3$ & $16.8 \pm 5.1$ & $31.9 \pm 0.9$ & $7.5 \pm 0.3$ \\
\hline N. salina \& P. triconutum, N:P & $21.2 \pm 1.7$ & $24.97 \pm 2.7$ & $24.8 \pm 3.9$ & $7.7 \pm 0.2$ \\
\hline N. salina, N:P & $19.0 \pm 3.0$ & $25.6 \pm 2.8$ & $29.0 \pm 5.2$ & $7.56 \pm 0.1$ \\
\hline P. triconutum, N:P & $11.28 \pm 5.5$ & $17.0 \pm 7.0$ & $30.3 \pm 0.7$ & 7 \\
\hline
\end{tabular}

\section{Lab-scale cultivation parameters}

Culture tube diameter $=25 \mathrm{~mm}$

Culture tube length $=2030 \mathrm{~mm}$

Culture volume $=90 \mathrm{~mL}$

Headspace $=10 \mathrm{~mL}$

Water bath volume $=4 \mathrm{~L}$

Light source $=$ white strip LED aligned $12.5 \mathrm{~mm}$ from long axis edge of culture tube 